\title{
Reference percentiles for mid-upper arm circumference, upper arm muscle and fat areas in the Argentine child and adolescent population (4-14 years old)
}

a. Adaptation and Ontogenesis Research Laboratory, School of Natural Sciences and Museum.

b. Veterinarian Genetics Institute, School of

Veterinary Sciences.ScientificTechnological Center (Centro Científico Tecnológico, CCT), National Scientific and Technical Research Council La Plata, Buenos Aires.

c. Institute of Anthropological Sciences, School of

Philosophy and Literature, Universidad de Buenos Aires, Argentina.

d. Institute of Ecoregions of the Andes, Universidad Nacional de Jujuy (UNJu)-CONICET.

Institute for High Altitude Biology, UNJu.

Unit of Biological Anit of Biological School of Humanities and Social Sciences, UNJu.

g. Laboratory of Biological Anthropology, Institute of Southern Diversity and of Southem Diversity and Evolution, CCT-National Patagonian Cent CONICET.

h. School of Natural Sciences and Health, Universidad Nacional San Juan Bosco (UNPSJB).

i. Center of Biological Anthropology Studies,
Universidad Nacional de Catamarca (UNCA).

Regional Institute of Sociocultural Studies, CONICET-UNCA.

k. Center of Parasitological and Vector Investigations, UNLPCCT, CONICET. Argentina. CCT, CONICET. Argentina.
Research Group for Nutrition

Research Group for Nutrition
Epidemiology, Department of Biodiversity, Ecology and Evolution, School of Biological Sciences, Universidad Complutense de Madrid, Spain.

E-mail address:

Evelia E. Oyhenart, M.D. oyhenart@fcnym.unlp.edu.ar

Funding:

In Argentina, funds were

provided by the National Agency

of Scientific and Technological

of Scientific and Technological

Promotion (Agencia Nacion

de Promoción Científica y

01541; PICT 07391; PICTO 00139;

PICTO 32451), the National

Scientific and Technical Research

Council (Consejo Nacional de

Investigaciones Científicas y

Técnicas [CONICET]: PIP 0106)

and the Department of Science

and Technology (Secretaría de

Ciencia y Técnica [SECyT]: UNLP

11N/679; UNCA L449; UNJu

F0013; UNPSJB C30); in Spain

funds were provided by the

Ministry of Education and Science

of Spain (05372).

Conflict of interest:

None.

Received: 9-2-2018

Accepted: 1-31-2019

\author{
Evelia E. Oyhenart, M.D. ${ }^{a, b}$, María F. Torres, M.D. ${ }^{b, c}$, Mariela Garraza, M.D. ${ }^{a, b}$, \\ María F. Cesani, M.D. ${ }^{a, b}$, Bárbara Navazo, B.S. ${ }^{a, b}$, Luis E. Castro, M.D. ${ }^{a}$, \\ Emma Alfaro, M.D. ${ }^{d, e}$, Ignacio F. Bejarano, Magisteref, Rafael Carrillo, B.S. e,f, \\ Silvia L. Dahinten, M.D. ${ }^{g, h}$, Delia Lomaglio, M.D. ${ }^{i, j}$, María A. Luis, B.S. ${ }^{a}$, \\ Natalia Menecier, B.S. ${ }^{i}$, Fabián A. Quintero, M.D. ${ }^{a, b}$, Estela M. Román, B.S. ${ }^{d, e}$, \\ María L. Zonta, M.D. ${ }^{,}$María D. Marrodán Serrano, M.D. ${ }^{l}$ and \\ José E. Dipierri, M.D. d,e
}

\section{ABSTRACT}

Introduction: Mid-upper arm circumference (MUAC) is widely recognized as an adequate indicator of nutritional status.

Objective: To estimate the reference percentiles for MUAC, upper arm muscle area (UAMA), and upper arm fat area (UAFA) in the Argentine child and adolescent population using the LMS method (lambda, mu, sigma)

Materials and methods: The sample was made up of schoolchildren aged 4.0-13.9 years living in Jujuy, Catamarca, Misiones, Buenos Aires, Mendoza, and Chubut. MUAC and tricipital skinfold anthropometric measurements were obtained between 2003 and 2008 as per standardized protocols. UAMA and UAFA were calculated, and percentiles by age and sex were estimated and compared using an analysis of variance.

Results: A total of 22736 schoolchildren (11 397 boys and 11339 girls) were included. The $50^{\text {th }}$ percentile was higher for the MUAC and UAFA among girls and for the UAMA among boys. The MUAC curves showed sharper increases as of 7 years old in all percentiles among both boys and girls. A similar pattern was observed for the UAMA, with higher values among boys. Lastly, the UAFA showed a constant increase among girls and a stabilization among boys as of 11 years old. Differences for age were observed.

Conclusions: The tabulated and plotted percentiles and the MUAC, UAMA, and UAFA may be used as local references for epidemiological and anthropological studies. Key words: reference values, anthropometry, body composition, Argentina, LMS method.

http: / / dx.doi.org/10.5546/ aap.2019.eng.e347

To cite: Oyhenart EE, Torres MF, Garraza M, Cesani MF, et al. Reference percentiles for mid-upper arm circumference, upper arm muscle and fat areas in the Argentine child and adolescent population (4-14 years old). Arch Argent Pediatr 2019;117(4):e347-e355.

\section{INTRODUCTION}

Anthropometric measurements are valuable tools to assess growth and nutritional status because they are methodologically simple and low cost for large scale studies. ${ }^{1}$ In this regard, for comparison purposes, it is important to have reference values that reflect, whenever possible, population variability.

Previous auxological assessments conducted in Argentine population groups have demonstrated that their growth patterns are heterogeneous. Such diversity is mainly attributed to the effect of environmental factors, such as geographic, meteorological, economic, social, and cultural factors that outline the vast national territory. ${ }^{2-5}$

Since 1920, mid-upper arm circumference (MUAC) has been recognized as an indicator of nutritional status for populations in different regions worldwide. ${ }^{6}$ This anthropometric measure is particularly useful in emergency situations that require a rapid field assessment, ${ }^{7,8}$ in isolated settings where there are no stadiometers, scales or other measurement instruments, ${ }^{9,10}$ in famine or refugee crisis situations where height and weight are hard to determine, especially in malnourished children, ${ }^{11}$ or when the measurement of body weight is considered inadequate because it may induce body image issues associated with an ideal body model. ${ }^{12}$ Likewise, the MUAC has been used as an additional screening 
and prevention tool because it is capable of predicting infant mortality ${ }^{13}$ due to its reliability, low possibility of error between observers, and easy suitability for being recorded by health care agents.

Recent studies have demonstrated that, in addition to the traditional use of MUAC to estimate malnutrition, it is greatly useful for clinical assessment and epidemiological surveillance of obesity in developing countries.,10,14 The combination of MUAC and tricipital skinfold (TSF) allows to estimate, in an indirect manner, the upper arm fat area (UAFA) and the upper arm lean mass. ${ }^{7}$ Estimating these body composition parameters enables to know calorie and protein reserves and also to identify risk factors related to malnutrition, both by excess and deficiency. ${ }^{15}$ The reliability of estimations made using the upper arm anthropometry has been validated with magnetic resonance imaging approximately two decades ago and has demonstrated a high correlation, especially, UAFA. ${ }^{16}$

Since 1976, the National Health Survey has published, together with other anthropometric measures, the percentiles for MUAC in boys and girls in the United States population aged 2 months to 19 years. ${ }^{17}$ However, while in the first place the World Health Organization (WHO) had not recommended or included the MUAC in the growth charts for children aged 5-19 years, ${ }^{13,18}$ it was considered among the Multicentre Growth Reference Study Group measures for children aged $0-5$ years. ${ }^{19}$

For the analysis of mid-upper arm body composition using the MUAC and its derivative outcome measures, upper arm muscle area (UAMA) and UAFA, there are widely used references, as the one proposed by Frisancho ${ }^{20}$ and the more recent one published by Addo et al., ${ }^{21}$ based on national surveys on the health of the American population. In Argentina, to date, the only MUAC reference values available correspond to the Córdoba ${ }^{22}$ and Buenos Aires ${ }^{8}$ populations.

In this context, and considering the aspects mentioned before, the objective of this study was to estimate the reference percentiles for MUAC, and the UAMA and UAFA values in the Argentine child and adolescent population.

\section{POPULATION AND METHODS Population}

The sample was made up by schoolchildren attending kindergarten, primary and secondary school living in six provinces from the five Argentine geographic regions: Jujuy and Catamarca (Northwest region), Misiones (Northeast region), Buenos Aires (Central region), Mendoza (Cuyo), and Chubut (Patagonia). The sampling was selected by convenience, in a non-probabilistic fashion. The following cities and towns from each province were included: San Salvador de Jujuy, Susques, Fraile Pintado, and Humahuaca (Jujuy); San Fernando del Valle de Catamarca, and El Peñón (Catamarca); Aristóbulo del Valle (Misiones); Brandsen, La Plata, Magdalena, and Punta Indio (Buenos Aires); General Alvear and San Rafael (Mendoza); Puerto Madryn (Chubut). The authorization to enter schools was requested to each district's school authorities. The eligible population included all schoolchildren from 4.0 to 13.9 years of age who attended school on the day of the anthropometric assessment and who submitted a written authorization from their parents / guardians. Children with chronic or acute conditions or receiving drug treatment at the time of the study were excluded, as well as those who failed to submit a written authorization from their parents / guardians, and those who refused to take part in the study, even if they had their parents' / guardians' authorization.

\section{METHODS}

A descriptive, cross-sectional design was used in this study. Measurements were taken at public schools during the 2003-2008 period as per the standardized protocols proposed by the International Society for the Advancement of Kinanthropometry (ISAK). ${ }^{23}$ Using the left arm, in a relaxed state, the MUAC was measured in centimeters using a non-extensible tape measure with a $1 \mathrm{~mm}$ precision, while the TSF was taken in millimeters using a Lange caliper with constant pressure and a $1 \mathrm{~mm}$ precision. Instruments were calibrated at the beginning of each anthropometric session. All anthropometric measures were taken by the authors, who are specialists trained in anthropometric techniques. Before data collection, all anthropometrists got together and estimated the intra- and interobserver error, which was below $5 \%$, thus ensuring measurement standardization. ${ }^{23}$

Based on collected anthropometric outcome measures, the total area (TA), UAMA, and UAFA of the arm were estimated using the formulas proposed by Frisancho: ${ }^{20}$

$$
\mathrm{TA}=\left[(\pi / 4) \times\left(\mathrm{MUAC} / \pi^{2}\right)\right]
$$


$\mathrm{UAMA}=(\mathrm{MUAC}-\pi \times \mathrm{TSF})^{2} / 4 \pi$

$\mathrm{UAFA}=\mathrm{TA}$ - UAMA

Each child's decimal age was estimated based on the date of birth obtained from their national identity document or school records and the date of measurement.

\section{Statistical analysis}

Data were grouped by sex and decimal age. Each decimal year was divided by two, thus resulting in 21 age ranges. Crude data dispersion was analyzed and extreme measures were removed using \pm 4 standard deviations (SDs) as cut-off point. ${ }^{2}$ Based on this criterion, 42 cases were removed from the total $(0.18 \%)$.

The LMS method was used to calculate percentiles. This method summarizes the changes in the distribution of anthropometric measures based on age using the lambda (L), mu (M), and sigma (S) curves, which account for asymmetry, median, and variance, respectively. It uses a BoxCox transformation (L) to adapt anthropometric data distribution to a normal distribution by minimizing mainly the effects of asymmetry but not kurtosis. ${ }^{24}$ The L, M, and S parameters were estimated according to the maximum penalized likelihood procedure. ${ }^{24}$

Percentiles (P) were estimated based on the following formula: ${ }^{25}$

$\mathrm{P}=\mathrm{M}[1+\mathrm{LSZ}]^{1 / \mathrm{L}}$

Where $\mathrm{L}, \mathrm{M}$, and $\mathrm{S}$ corresponded to the values estimated for each age and the $Z$-score $(Z)$ corresponded to the targeted percentile. The $\mathrm{Q}$ test was used to estimate the goodness-of-fit. Schoolchildren's decimal age was used and the curves were set so that the $Y$ axis showed age in whole numbers and the equidistant points between whole numbers.

Data were processed using the LMS chart Maker Pro software. This version allowed to adjust models considering the weight of samples and group selection. Likewise, it allowed to estimate the goodness-of-fit using the $Q$ test. The $\mathrm{L}, \mathrm{M}$, and $\mathrm{S}$ degrees of freedom used to adjust the curve corresponded to 3-5-3, respectively. Curves were plotted using the R 3.2.0 software.

The percentiles estimated by age for MUAC, UAMA and UAFA, for each sex, were compared using plots and studied with an analysis of variance (ANOVA).

\section{Ethical considerations}

Research was done in accordance with the 1948 Universal Declaration of Human Rights, the ethical standards established by the 1947 Nuremberg Code, and the 1964 Declaration of Helsinki, as amended, with special attention to the provisions of the Protection of Personal Information Act (no. 25326).

The study was approved by the committee of Hospital de la Escuela Interzonal "San Juan Bautista" of Catamarca, the Bioethics Committee of the province of Jujuy, and the Bioethics Committee of the Latin American School of Bioethics (Escuela Latinoamericana de Bioética, CELABE) for the province of Buenos Aires, Chubut, Mendoza, and Misiones.

\section{RESULTS}

The study included 22736 children (11 397 boys and 11339 girls) aged 4.0-13.9 years. Participant distribution was as follows: Jujuy, 1700 (842 boys and 858 girls); Catamarca, 941 (456 boys and 485 girls); Misiones, 2206 (1088 boys and 1118 girls); Buenos Aires, 8420 (4177 boys and 4243 girls); Mendoza, 6652 (3369 boys and 3283 girls), and Chubut, 2817 (1465 boys and 1352 girls).

The sample representation by age and sex was as follows: $4.0-4.9$ years (1238: 637 boys, 601 girls), 5.0-5.9 years (1940: 1015 boys, 925 girls), 6.0-6.9 years (2405: 1253 boys, 1152 girls), 7.0-7.9 years (2510: 1292 boys, 1218 girls), 8.08.9 years (2649: 1284 boys, 1365 girls), 9.0-9.9 years (2720: 1375 boys, 1345 girls), 10.0-10.9 years (2631: 1275 boys, 1356 girls), 11.0-11.9 years (2593: 1276 boys, 1317 girls), 12.0-12.9 years (2319: 1117 boys, 1202 girls), and 13.0-13.9 years (1731: 873 boys, 858 girls).

Tables 1-3 and Figures 1-3 show values in a 9-percentile format: $3^{\text {rd }}, 5^{\text {th }}, 10^{\text {th }}, 25^{\text {th }}, 50^{\text {th }}, 75^{\text {th }}$, $90^{\text {th }}, 95^{\text {th }}$, and $97^{\text {th }}$, corresponding to the MUAC, UAMA, and UAFA for boys and girls aged 4-14 years, classified into 6-month periods. The tables also show the $\mathrm{L}$ and $\mathrm{S}$ parameters.

In general, the $50^{\text {th }}$ percentile was higher for the MUAC and UAFA among girls and for the UAMA among boys (Tables 1-3).

The MUAC curves showed more marked increases as of 7 years old in all percentiles among both boys and girls (Figure 1). A similar pattern was observed for the UAMA, with higher values among boys (Figure 2). Lastly, the UAFA showed a constant increase among girls and a stabilization among boys as of 11 years old (Figure 3).

Statistically significant differences were observed in all age comparisons. For MUAC, among boys: $\mathrm{F}=2.515, p<0.0001$; among girls: 
$\mathrm{F}=2.769, p<0.0001$; for UAMA, among boys: $\mathrm{F}=3.405, p<0.0001 ;$ among girls: $\mathrm{F}=3.485$, $p<0.0001$; for UAFA, among boys: $\mathrm{F}=1.260$, $p<0.0001$; among girls: $\mathrm{F}=1.425, p<0.0001$.

\section{DISCUSSION}

This is the first study that provides smoothed percentile curves using the LMS method for the MUAC and derivative measures in a sample of more than 22000 boys and girls from six provinces of Argentina. These anthropometric measures are dependent on age and sex, so this study provides not only percentiles, but also the lambda, mu, and sigma values, which are useful to estimate the Z-scores in both males and females at any age in the 4-14 year-old range.

The MUAC and the weight for height values have been traditionally used to define severe malnutrition in children younger than 5 years old. However, for the MUAC, the $\mathrm{WHO}^{26}$ has proposed a single cut-off point, regardless of age and sex, corresponding to a value under $115 \mathrm{~mm}$. According to what has been stated by AbdelRahman et al., ${ }^{27}$ this may lead to overdiagnosing

TABLE 1. Percentiles (P), asymmetry (L), and coefficient of variation (S) for mid-upper arm circumference (cm) among boys and girls

\begin{tabular}{|c|c|c|c|c|c|c|c|c|c|c|c|}
\hline Age (years old) & $\mathbf{L}$ & $\mathrm{S}$ & P3 & P5 & P10 & $\mathrm{P} 25$ & P50 & P75 & P90 & P95 & P97 \\
\hline \multicolumn{12}{|l|}{ Boys } \\
\hline 4.0 & -2.4023 & 0.0843 & 14.70 & 14.92 & 15.28 & 15.94 & 16.81 & 17.86 & 19.02 & 19.85 & 20.46 \\
\hline 4.5 & -2.5126 & 0.0864 & 14.83 & 15.05 & 15.41 & 16.09 & 16.99 & 18.08 & 19.31 & 20.20 & 20.87 \\
\hline 5.0 & -2.6094 & 0.0886 & 14.95 & 15.17 & 15.54 & 16.23 & 17.15 & 18.29 & 19.59 & 20.55 & 21.27 \\
\hline 5.5 & -2.6723 & 0.0909 & 15.03 & 15.26 & 15.63 & 16.34 & 17.29 & 18.47 & 19.84 & 20.87 & 21.65 \\
\hline 6.0 & -2.6917 & 0.0934 & 15.07 & 15.30 & 15.69 & 16.41 & 17.39 & 18.62 & 20.06 & 21.15 & 21.99 \\
\hline 6.5 & -2.6721 & 0.0963 & 15.12 & 15.36 & 15.75 & 16.50 & 17.51 & 18.79 & 20.30 & 21.45 & 22.35 \\
\hline 7.0 & -2.6350 & 0.0995 & 15.22 & 15.47 & 15.87 & 16.65 & 17.70 & 19.03 & 20.63 & 21.86 & 22.81 \\
\hline 7.5 & -2.5920 & 0.1031 & 15.38 & 15.63 & 16.05 & 16.86 & 17.96 & 19.37 & 21.07 & 22.38 & 23.42 \\
\hline 8.0 & -2.5368 & 0.1067 & 15.58 & 15.84 & 16.29 & 17.13 & 18.29 & 19.78 & 21.59 & 23.00 & 24.12 \\
\hline 8.5 & -2.4538 & 0.1106 & 15.82 & 16.10 & 16.56 & 17.45 & 18.67 & 20.26 & 22.18 & 23.69 & 24.89 \\
\hline 9.0 & -2.3352 & 0.1146 & 16.07 & 16.36 & 16.85 & 17.80 & 19.09 & 20.77 & 22.81 & 24.41 & 25.68 \\
\hline 9.5 & -2.1857 & 0.1187 & 16.30 & 16.62 & 17.13 & 18.14 & 19.51 & 21.28 & 23.43 & 25.11 & 26.44 \\
\hline 10.0 & -2.0179 & 0.1226 & 16.51 & 16.85 & 17.40 & 18.46 & 19.91 & 21.78 & 24.02 & 25.76 & 27.12 \\
\hline 10.5 & -1.8499 & 0.1259 & 16.72 & 17.07 & 17.66 & 18.78 & 20.30 & 22.25 & 24.57 & 26.35 & 27.72 \\
\hline 11.0 & -1.6813 & 0.1286 & 16.92 & 17.29 & 17.90 & 19.08 & 20.68 & 22.70 & 25.07 & 26.86 & 28.23 \\
\hline 11.5 & -1.5160 & 0.1307 & 17.10 & 17.49 & 18.14 & 19.38 & 21.04 & 23.12 & 25.52 & 27.31 & 28.65 \\
\hline 12.0 & -1.3531 & 0.1319 & 17.33 & 17.74 & 18.42 & 19.71 & 21.42 & 23.56 & 25.97 & 27.74 & 29.05 \\
\hline 12.5 & -1.1754 & 0.1325 & 17.59 & 18.02 & 18.73 & 20.07 & 21.85 & 24.02 & 26.43 & 28.16 & 29.42 \\
\hline 13.0 & -0.9772 & 0.1323 & 17.88 & 18.34 & 19.09 & 20.49 & 22.31 & 24.51 & 26.90 & 28.57 & 29.78 \\
\hline 13.5 & -0.7580 & 0.1315 & 18.21 & 18.69 & 19.48 & 20.94 & 22.82 & 25.03 & 27.37 & 28.98 & 30.12 \\
\hline 14.0 & -0.5243 & 0.1305 & 18.55 & 19.06 & 19.89 & 21.41 & 23.34 & 25.55 & 27.85 & 29.39 & 30.46 \\
\hline \multicolumn{12}{|l|}{ Girls } \\
\hline 4.0 & -1.8595 & 0.0886 & 14.74 & 14.98 & 15.37 & 16.09 & 17.02 & 18.12 & 19.31 & 20.14 & 20.74 \\
\hline 4.5 & -1.8010 & 0.0911 & 14.77 & 15.01 & 15.42 & 16.16 & 17.12 & 18.26 & 19.50 & 20.36 & 20.98 \\
\hline 5.0 & -1.7504 & 0.0937 & 14.79 & 15.05 & 15.46 & 16.23 & 17.23 & 18.41 & 19.69 & 20.58 & 21.22 \\
\hline 5.5 & -1.7076 & 0.0965 & 14.82 & 15.08 & 15.51 & 16.30 & 17.33 & 18.56 & 19.89 & 20.82 & 21.49 \\
\hline 6.0 & -1.6716 & 0.0994 & 14.85 & 15.12 & 15.56 & 16.39 & 17.45 & 18.72 & 20.11 & 21.08 & 21.78 \\
\hline 6.5 & -1.6682 & 0.1022 & 14.92 & 15.20 & 15.66 & 16.50 & 17.61 & 18.93 & 20.38 & 21.40 & 22.14 \\
\hline 7.0 & -1.7061 & 0.1053 & 15.06 & 15.35 & 15.82 & 16.70 & 17.84 & 19.23 & 20.76 & 21.85 & 22.64 \\
\hline 7.5 & -1.7482 & 0.1088 & 15.25 & 15.55 & 16.03 & 16.94 & 18.14 & 19.60 & 21.24 & 22.41 & 23.28 \\
\hline 8.0 & -1.7681 & 0.1125 & 15.46 & 15.77 & 16.27 & 17.22 & 18.48 & 20.02 & 21.77 & 23.04 & 23.99 \\
\hline 8.5 & -1.7594 & 0.1160 & 15.70 & 16.02 & 16.54 & 17.53 & 18.85 & 20.49 & 22.36 & 23.72 & 24.75 \\
\hline 9.0 & -1.7148 & 0.1189 & 15.95 & 16.28 & 16.83 & 17.86 & 19.25 & 20.97 & 22.93 & 24.38 & 25.47 \\
\hline 9.5 & -1.6414 & 0.1212 & 16.19 & 16.53 & 17.10 & 18.18 & 19.62 & 21.41 & 23.46 & 24.96 & 26.08 \\
\hline 10.0 & -1.5409 & 0.1229 & 16.42 & 16.78 & 17.37 & 18.49 & 19.99 & 21.84 & 23.93 & 25.47 & 26.61 \\
\hline 10.5 & -1.4116 & 0.1242 & 16.67 & 17.05 & 17.66 & 18.83 & 20.38 & 22.27 & 24.41 & 25.95 & 27.08 \\
\hline 11.0 & -1.2589 & 0.1247 & 16.96 & 17.35 & 18.00 & 19.21 & 20.81 & 22.74 & 24.89 & 26.42 & 27.53 \\
\hline 11.5 & -1.0900 & 0.1243 & 17.28 & 17.69 & 18.37 & 19.63 & 21.27 & 23.23 & 25.37 & 26.86 & 27.94 \\
\hline 12.0 & -0.9385 & 0.1232 & 17.65 & 18.08 & 18.78 & 20.08 & 21.76 & 23.74 & 25.85 & 27.31 & 28.34 \\
\hline 12.5 & -0.8052 & 0.1214 & 18.05 & 18.50 & 19.23 & 20.57 & 22.27 & 24.25 & 26.34 & 27.75 & 28.75 \\
\hline 13.0 & -0.6971 & 0.1192 & 18.48 & 18.94 & 19.68 & 21.05 & 22.77 & 24.75 & 26.81 & 28.18 & 29.14 \\
\hline 13.5 & -0.6224 & 0.1167 & 18.91 & 19.38 & 20.14 & 21.52 & 23.25 & 25.23 & 27.25 & 28.59 & 29.52 \\
\hline 14.0 & -0.5705 & 0.1140 & 19.35 & 19.82 & 20.59 & 21.98 & 23.71 & 25.67 & 27.66 & 28.97 & 29.88 \\
\hline
\end{tabular}


or underestimating acute malnutrition in the age group younger than 5 years, thus effectively reducing the sensitivity of this measure. However, other authors have proposed that a $<134 \mathrm{~mm}$ cut-off point is an indicator of risk and that a $125 \mathrm{~mm}$ and a $115 \mathrm{~mm}$ cut-off point would set the limit for moderate and severe malnutrition, respectively. ${ }^{28}$ For this reason, a diagnosis based on the MUAC using the LMS method, as used in this study and in those by Addo et al., ${ }^{21}$ and Abdel-Rahman et al., ${ }^{27}$ would be more accurate because it would allow to define new cut-off points specific for age and sex.
In addition, the strong correlation between the MUAC and several adiposity indicators (weight and body mass index, body fat percentage and waist circumference) would also help to assess overweight and obesity in children between 9 and 11 years old. ${ }^{10}$ Based on the receiver operating characteristic (ROC) curve analysis, Craig et al., ${ }^{29}$ proposed different cut-off points for the MUAC to identify overweight by age and sex. Nevertheless, cut-off points may vary depending on the ethnic origin of populations, ${ }^{10}$ for this reason, given that there is no standard reference, it is recommended to have local references available.

TABLE 2. Percentiles $(P)$, asymmetry $(L)$, and coefficient of variation $(S)$ for upper arm muscle area $\left(\mathrm{cm}^{2}\right)$ among boys and girls

\begin{tabular}{|c|c|c|c|c|c|c|c|c|c|c|c|}
\hline Age (years old & d) $\mathrm{L}$ & $\mathrm{S}$ & P3 & P5 & P10 & P25 & P50 & P75 & P90 & P95 & P97 \\
\hline \multicolumn{12}{|l|}{ Boys } \\
\hline 4.0 & -0.0922 & 0.1611 & 10.64 & 11.04 & 11.68 & 12.85 & 14.31 & 15.94 & 17.60 & 18.67 & 19.41 \\
\hline 4.5 & -0.0655 & 0.1649 & 10.94 & 11.36 & 12.05 & 13.29 & 14.83 & 16.57 & 18.33 & 19.47 & 20.25 \\
\hline 5.0 & -0.0371 & 0.1687 & 11.22 & 11.67 & 12.39 & 13.71 & 15.34 & 17.18 & 19.04 & 20.25 & 21.07 \\
\hline 5.5 & -0.0084 & 0.1726 & 11.45 & 11.92 & 12.68 & 14.07 & 15.79 & 17.73 & 19.68 & 20.95 & 21.82 \\
\hline 6.0 & 0.0189 & 0.1767 & 11.63 & 12.12 & 12.92 & 14.37 & 16.18 & 18.20 & 20.25 & 21.57 & 22.48 \\
\hline 6.5 & 0.0419 & 0.1811 & 11.78 & 12.29 & 13.13 & 14.65 & 16.54 & 18.67 & 20.80 & 22.19 & 23.14 \\
\hline 7.0 & 0.0509 & 0.1861 & 11.96 & 12.50 & 13.38 & 14.98 & 16.97 & 19.21 & 21.46 & 22.93 & 23.93 \\
\hline 7.5 & 0.0362 & 0.1913 & 12.20 & 12.76 & 13.68 & 15.37 & 17.47 & 19.85 & 22.25 & 23.81 & 24.88 \\
\hline 8.0 & -0.0072 & 0.1958 & 12.48 & 13.07 & 14.03 & 15.79 & 18.01 & 20.53 & 23.09 & 24.78 & 25.94 \\
\hline 8.5 & -0.0807 & 0.1995 & 12.85 & 13.46 & 14.44 & 16.27 & 18.59 & 21.26 & 24.02 & 25.84 & 27.10 \\
\hline 9.0 & -0.1530 & 0.2028 & 13.28 & 13.90 & 14.91 & 16.80 & 19.23 & 22.06 & 25.01 & 26.99 & 28.38 \\
\hline 9.5 & -0.2030 & 0.2063 & 13.72 & 14.35 & 15.40 & 17.36 & 19.90 & 22.89 & 26.06 & 28.20 & 29.70 \\
\hline 10.0 & -0.2218 & 0.2109 & 14.10 & 14.76 & 15.85 & 17.90 & 20.58 & 23.75 & 27.13 & 29.43 & 31.05 \\
\hline 10.5 & -0.2122 & 0.2163 & 14.45 & 15.14 & 16.29 & 18.45 & 21.27 & 24.64 & 28.24 & 30.71 & 32.45 \\
\hline 11.0 & -0.1777 & 0.2225 & 14.78 & 15.51 & 16.73 & 19.02 & 22.02 & 25.60 & 29.44 & 32.06 & 33.91 \\
\hline 11.5 & -0.1251 & 0.2292 & 15.13 & 15.92 & 17.22 & 19.67 & 22.89 & 26.72 & 30.81 & 33.59 & 35.56 \\
\hline 12.0 & -0.0377 & 0.2364 & 15.56 & 16.41 & 17.83 & 20.51 & 23.99 & 28.12 & 32.49 & 35.45 & 37.52 \\
\hline 12.5 & 0.0779 & 0.2438 & 16.04 & 17.00 & 18.58 & 21.54 & 25.36 & 29.83 & 34.49 & 37.61 & 39.78 \\
\hline 13.0 & 0.1988 & 0.2506 & 16.60 & 17.67 & 19.45 & 22.75 & 26.96 & 31.81 & 36.78 & 40.05 & 42.31 \\
\hline 13.5 & 0.3280 & 0.2574 & 17.14 & 18.37 & 20.37 & 24.07 & 28.71 & 33.96 & 39.24 & 42.67 & 45.01 \\
\hline 14.0 & 0.4646 & 0.2645 & 17.57 & 18.97 & 21.25 & 25.40 & 30.52 & 36.20 & 41.80 & 45.37 & 47.78 \\
\hline \multicolumn{12}{|l|}{ Girls } \\
\hline 4.0 & 0.2445 & 0.1692 & 10.02 & 10.46 & 11.16 & 12.42 & 13.93 & 15.58 & 17.19 & 18.21 & 18.89 \\
\hline 4.5 & 0.2361 & 0.1721 & 10.19 & 10.64 & 11.37 & 12.67 & 14.25 & 15.96 & 17.64 & 18.71 & 19.43 \\
\hline 5.0 & 0.2166 & 0.1751 & 10.37 & 10.84 & 11.59 & 12.94 & 14.57 & 16.36 & 18.11 & 19.23 & 19.98 \\
\hline 5.5 & 0.1742 & 0.1781 & 10.57 & 11.05 & 11.82 & 13.21 & 14.91 & 16.77 & 18.61 & 19.79 & 20.59 \\
\hline 6.0 & 0.1013 & 0.1810 & 10.80 & 11.29 & 12.08 & 13.50 & 15.26 & 17.22 & 19.16 & 20.41 & 21.26 \\
\hline 6.5 & 0.0064 & 0.1838 & 11.06 & 11.56 & 12.36 & 13.82 & 15.64 & 17.69 & 19.75 & 21.09 & 22.01 \\
\hline 7.0 & -0.0828 & 0.1869 & 11.36 & 11.86 & 12.68 & 14.18 & 16.06 & 18.21 & 20.41 & 21.86 & 22.86 \\
\hline 7.5 & -0.1445 & 0.1909 & 11.63 & 12.14 & 12.98 & 14.52 & 16.48 & 18.75 & 21.09 & 22.65 & 23.73 \\
\hline 8.0 & -0.1835 & 0.1960 & 11.88 & 12.40 & 13.26 & 14.87 & 16.92 & 19.32 & 21.83 & 23.51 & 24.68 \\
\hline 8.5 & -0.2097 & 0.2015 & 12.14 & 12.69 & 13.59 & 15.27 & 17.44 & 19.99 & 22.68 & 24.49 & 25.77 \\
\hline 9.0 & -0.2210 & 0.2067 & 12.43 & 13.00 & 13.95 & 15.71 & 18.01 & 20.72 & 23.60 & 25.56 & 26.94 \\
\hline 9.5 & -0.2343 & 0.2111 & 12.77 & 13.37 & 14.35 & 16.21 & 18.63 & 21.52 & 24.59 & 26.69 & 28.17 \\
\hline 10.0 & -0.2715 & 0.2145 & 13.20 & 13.82 & 14.85 & 16.79 & 19.34 & 22.40 & 25.69 & 27.95 & 29.55 \\
\hline 10.5 & -0.3019 & 0.2168 & 13.73 & 14.38 & 15.45 & 17.48 & 20.16 & 23.40 & 26.91 & 29.35 & 31.08 \\
\hline 11.0 & -0.2964 & 0.2185 & 14.34 & 15.02 & 16.15 & 18.28 & 21.11 & 24.54 & 28.27 & 30.86 & 32.71 \\
\hline 11.5 & -0.2399 & 0.2196 & 14.98 & 15.70 & 16.90 & 19.16 & 22.16 & 25.76 & 29.67 & 32.36 & 34.28 \\
\hline 12.0 & -0.1599 & 0.2202 & 15.62 & 16.40 & 17.68 & 20.11 & 23.28 & 27.06 & 31.10 & 33.86 & 35.81 \\
\hline 12.5 & -0.0752 & 0.2204 & 16.29 & 17.12 & 18.50 & 21.09 & 24.44 & 28.39 & 32.55 & 35.37 & 37.33 \\
\hline 13.0 & -0.0031 & 0.2203 & 16.97 & 17.87 & 19.35 & 22.10 & 25.63 & 29.75 & 34.03 & 36.89 & 38.88 \\
\hline 13.5 & 0.0514 & 0.2201 & 17.69 & 18.65 & 20.22 & 23.13 & 26.85 & 31.13 & 35.55 & 38.48 & 40.50 \\
\hline 14.0 & 0.0972 & 0.2198 & 18.43 & 19.44 & 21.10 & 24.18 & 28.07 & 32.52 & 37.08 & 40.08 & 42.15 \\
\hline
\end{tabular}


In relation to what has been explained above, the MUAC of children analyzed in this study was, in general, higher than that reported by Lejarraga et al., ${ }^{8}$ for the $50^{\text {th }}$ and $97^{\text {th }}$ percentiles. Such difference may be related to what has been described by Guimarey et al. ${ }^{30}$ who reported, after 30 years, significant increases in the MUAC, TSF, and mid-upper arm fat area values in cohorts of children living in the city of La Plata, Buenos Aires.

The differences observed in the UAFA at all ages were in favor of girls, whereas the opposite was observed in relation to the UAMA, possibly due to the variation in the body composition typical of each sex. On this basis, the aggregate effects tended to compensate, and few differences were observed in the MUAC in terms of sex. ${ }^{8}$

One of the limitations of this study was that there were not data available on every stage of development. However, one of the main strengths of this study was that anthropometric data included an average of 2000 schoolchildren for each of the ten studied age ranges and that they represented different provinces with ecogeographic and socioeconomic variations. Future studies are required to define cut-off points for the assessment of malnutrition, both by excess and deficiency, and to validate these indicators based on their association with other

TABle 3. Percentiles $(P)$, asymmetry $(L)$, and coefficient of variation $(S)$ for upper arm fat area $\left(\mathrm{cm}^{2}\right)$ in boys and girls

\begin{tabular}{|c|c|c|c|c|c|c|c|c|c|c|c|}
\hline Age (years old) & l) $\mathrm{L}$ & $S$ & P3 & P5 & P10 & P25 & P50 & P75 & P90 & P95 & P97 \\
\hline \multicolumn{12}{|l|}{ Boys } \\
\hline 4.0 & -0.3827 & 0.3057 & 4.91 & 5.21 & 5.72 & 6.74 & 8.20 & 10.11 & 12.41 & 14.15 & 15.45 \\
\hline 4.5 & -0.3970 & 0.3239 & 4.77 & 5.07 & 5.59 & 6.64 & 8.16 & 10.20 & 12.71 & 14.64 & 16.12 \\
\hline 5.0 & -0.4107 & 0.3429 & 4.62 & 4.92 & 5.45 & 6.53 & 8.11 & 10.29 & 13.03 & 15.19 & 16.86 \\
\hline 5.5 & -0.4210 & 0.3629 & 4.45 & 4.75 & 5.29 & 6.38 & 8.03 & 10.34 & 13.32 & 15.72 & 17.61 \\
\hline 6.0 & -0.4234 & 0.3835 & 4.24 & 4.54 & 5.08 & 6.19 & 7.87 & 10.30 & 13.51 & 16.15 & 18.28 \\
\hline 6.5 & -0.4166 & 0.4044 & 4.06 & 4.36 & 4.90 & 6.03 & 7.77 & 10.33 & 13.78 & 16.68 & 19.06 \\
\hline 7.0 & -0.4023 & 0.4250 & 3.96 & 4.27 & 4.82 & 5.99 & 7.83 & 10.56 & 14.33 & 17.55 & 20.21 \\
\hline 7.5 & -0.3830 & 0.4442 & 3.95 & 4.28 & 4.86 & 6.10 & 8.07 & 11.05 & 15.22 & 18.81 & 21.81 \\
\hline 8.0 & -0.3576 & 0.4614 & 4.02 & 4.37 & 4.99 & 6.33 & 8.47 & 11.74 & 16.35 & 20.36 & 23.72 \\
\hline 8.5 & -0.3266 & 0.4762 & 4.14 & 4.51 & 5.18 & 6.64 & 8.98 & 12.58 & 17.66 & 22.08 & 25.77 \\
\hline 9.0 & -0.2937 & 0.4888 & 4.28 & 4.69 & 5.42 & 7.01 & 9.58 & 13.52 & 19.07 & 23.88 & 27.87 \\
\hline 9.5 & -0.2607 & 0.4997 & 4.43 & 4.87 & 5.67 & 7.39 & 10.19 & 14.47 & 20.48 & 25.64 & 29.89 \\
\hline 10.0 & -0.2268 & 0.5086 & 4.57 & 5.04 & 5.90 & 7.76 & 10.77 & 15.38 & 21.78 & 27.23 & 31.69 \\
\hline 10.5 & -0.1964 & 0.5156 & 4.68 & 5.18 & 6.09 & 8.08 & 11.30 & 16.18 & 22.91 & 28.56 & 33.15 \\
\hline 11.0 & -0.1759 & 0.5208 & 4.76 & 5.29 & 6.25 & 8.34 & 11.71 & 16.81 & 23.79 & 29.62 & 34.30 \\
\hline 11.5 & -0.1652 & 0.5247 & 4.81 & 5.35 & 6.34 & 8.49 & 11.97 & 17.22 & 24.39 & 30.34 & 35.11 \\
\hline 12.0 & -0.1641 & 0.5276 & 4.83 & 5.38 & 6.38 & 8.56 & 12.09 & 17.44 & 24.73 & 30.79 & 35.65 \\
\hline 12.5 & -0.1698 & 0.5297 & 4.82 & 5.37 & 6.36 & 8.55 & 12.09 & 17.47 & 24.83 & 30.97 & 35.90 \\
\hline 13.0 & -0.1799 & 0.5308 & 4.78 & 5.33 & 6.31 & 8.48 & 11.99 & 17.35 & 24.74 & 30.93 & 35.94 \\
\hline 13.5 & -0.1919 & 0.5303 & 4.75 & 5.28 & 6.25 & 8.38 & 11.85 & 17.16 & 24.52 & 30.73 & 35.77 \\
\hline 14.0 & -0.2043 & 0.5287 & 4.72 & 5.24 & 6.19 & 8.29 & 11.70 & 16.94 & 24.25 & 30.44 & 35.49 \\
\hline \multicolumn{12}{|l|}{ Girls } \\
\hline 4.0 & -0.2514 & 0.3061 & 5.44 & 5.79 & 6.39 & 7.57 & 9.23 & 11.37 & 13.85 & 15.67 & 17.01 \\
\hline 4.5 & -0.2332 & 0.3223 & 5.24 & 5.60 & 6.21 & 7.42 & 9.14 & 11.39 & 14.01 & 15.95 & 17.39 \\
\hline 5.0 & -0.2161 & 0.3397 & 5.04 & 5.40 & 6.02 & 7.28 & 9.06 & 11.42 & 14.21 & 16.28 & 17.82 \\
\hline 5.5 & -0.1979 & 0.3581 & 4.83 & 5.20 & 5.84 & 7.13 & 8.99 & 11.47 & 14.43 & 16.65 & 18.31 \\
\hline 6.0 & -0.1762 & 0.3770 & 4.64 & 5.01 & 5.67 & 7.00 & 8.93 & 11.54 & 14.69 & 17.05 & 18.84 \\
\hline 6.5 & -0.1560 & 0.3962 & 4.47 & 4.86 & 5.53 & 6.91 & 8.94 & 11.70 & 15.05 & 17.59 & 19.51 \\
\hline 7.0 & -0.1420 & 0.4157 & 4.41 & 4.81 & 5.51 & 6.97 & 9.14 & 12.11 & 15.77 & 18.56 & 20.67 \\
\hline 7.5 & -0.1303 & 0.4347 & 4.43 & 4.86 & 5.61 & 7.18 & 9.53 & 12.80 & 16.86 & 19.98 & 22.36 \\
\hline 8.0 & -0.1223 & 0.4506 & 4.52 & 4.98 & 5.78 & 7.47 & 10.04 & 13.64 & 18.16 & 21.65 & 24.33 \\
\hline 8.5 & -0.1240 & 0.4608 & 4.69 & 5.18 & 6.04 & 7.86 & 10.65 & 14.59 & 19.58 & 23.47 & 26.46 \\
\hline 9.0 & -0.1306 & 0.4652 & 4.93 & 5.44 & 6.35 & 8.29 & 11.27 & 15.52 & 20.93 & 25.18 & 28.46 \\
\hline 9.5 & -0.1313 & 0.4663 & 5.14 & 5.68 & 6.64 & 8.67 & 11.79 & 16.26 & 21.97 & 26.46 & 29.94 \\
\hline 10.0 & -0.1209 & 0.4666 & 5.31 & 5.87 & 6.86 & 8.97 & 12.21 & 16.83 & 22.72 & 27.35 & 30.92 \\
\hline 10.5 & -0.1020 & 0.4675 & 5.45 & 6.02 & 7.06 & 9.24 & 12.60 & 17.36 & 23.40 & 28.11 & 31.73 \\
\hline 11.0 & -0.0774 & 0.4682 & 5.57 & 6.17 & 7.25 & 9.53 & 13.01 & 17.92 & 24.09 & 28.87 & 32.51 \\
\hline 11.5 & -0.0480 & 0.4677 & 5.70 & 6.34 & 7.46 & 9.84 & 13.46 & 18.51 & 24.79 & 29.59 & 33.23 \\
\hline 12.0 & -0.0168 & 0.4654 & 5.87 & 6.53 & 7.72 & 10.21 & 13.96 & 19.15 & 25.50 & 30.31 & 33.92 \\
\hline 12.5 & 0.0131 & 0.4612 & 6.07 & 6.77 & 8.02 & 10.62 & 14.52 & 19.83 & 26.26 & 31.05 & 34.62 \\
\hline 13.0 & 0.0388 & 0.4541 & 6.31 & 7.05 & 8.35 & 11.07 & 15.08 & 20.49 & 26.94 & 31.70 & 35.22 \\
\hline 13.5 & 0.0598 & 0.4444 & 6.59 & 7.36 & 8.71 & 11.51 & 15.60 & 21.06 & 27.46 & 32.14 & 35.57 \\
\hline 14.0 & 0.0757 & 0.4336 & 6.89 & 7.69 & 9.08 & 11.93 & 16.08 & 21.52 & 27.85 & 32.42 & 35.75 \\
\hline
\end{tabular}



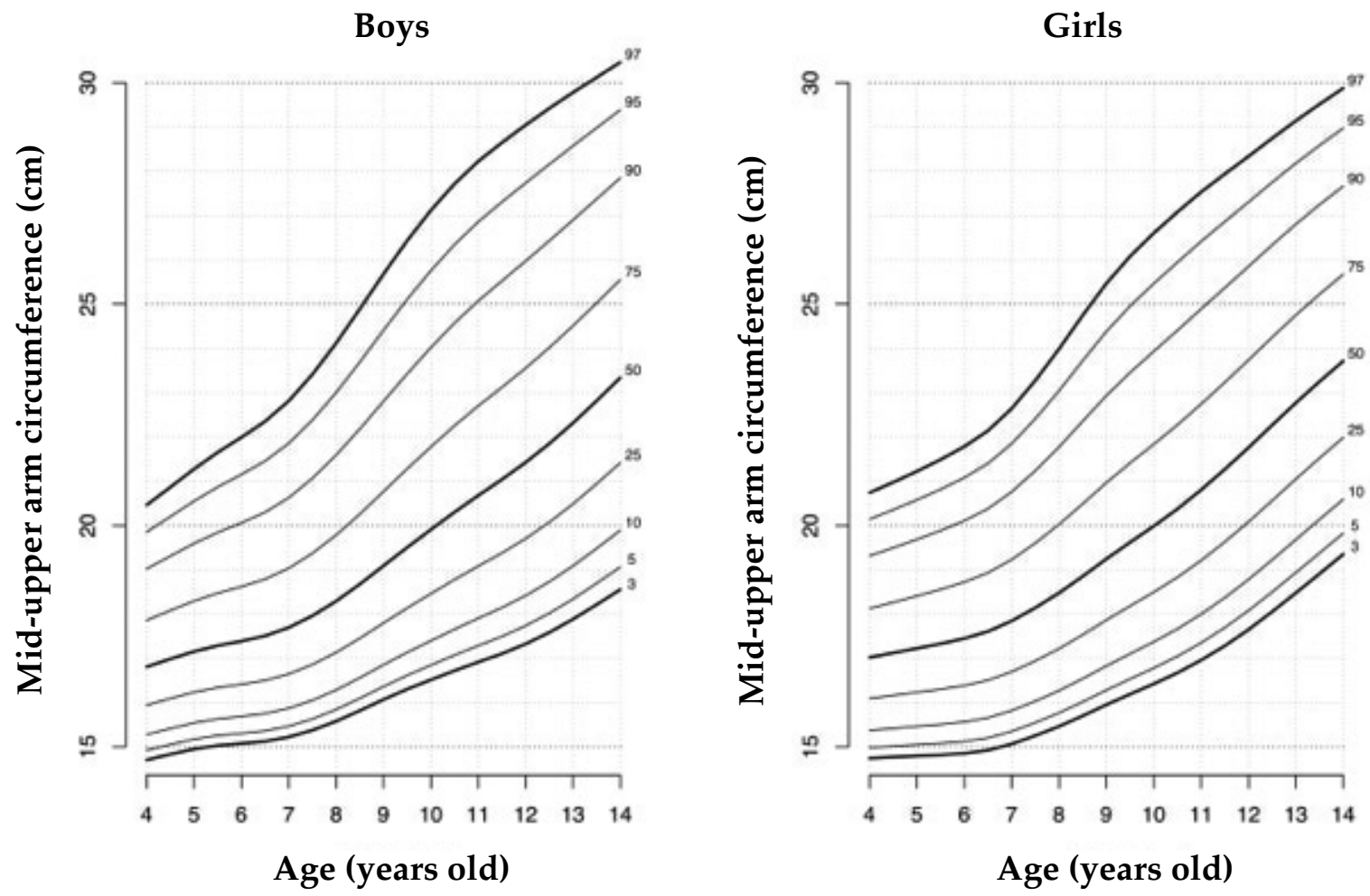

Figure 2. Percentiles for upper arm muscle area among boys and girls
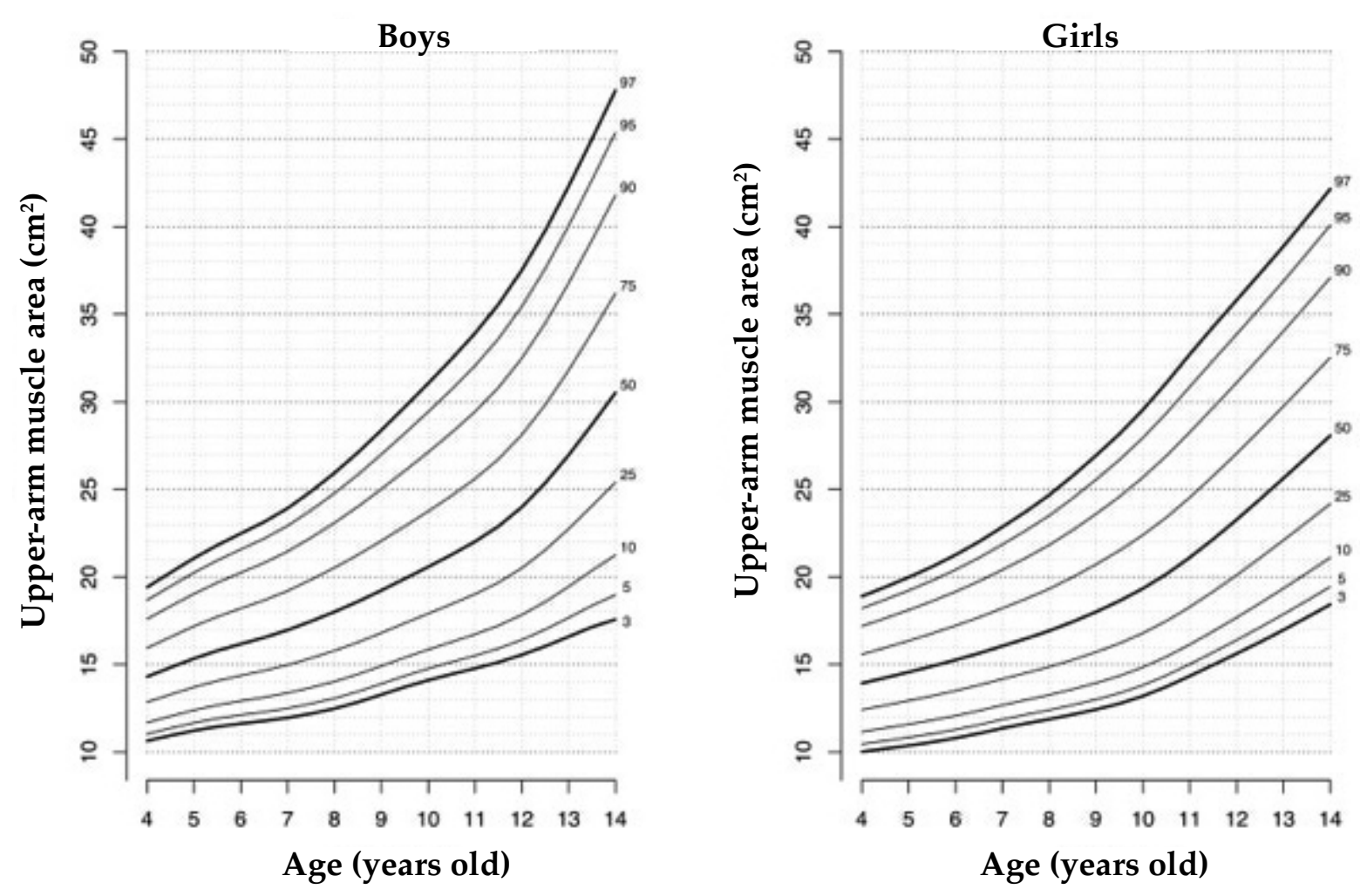
adiposity indicators. To conclude, tabulated and plotted percentiles and the MUAC, UAMA, and UAFA may be taken into consideration as local references for epidemiological and anthropological studies.

\section{Acknowledgments}

The authors would like to thank the children and their parents for their selfless collaboration; the school authorities and teachers who facilitated the field work at the schools; and the institutions that provided their financial support.

Figure 3. Percentiles for upper arm fat area among boys and girls

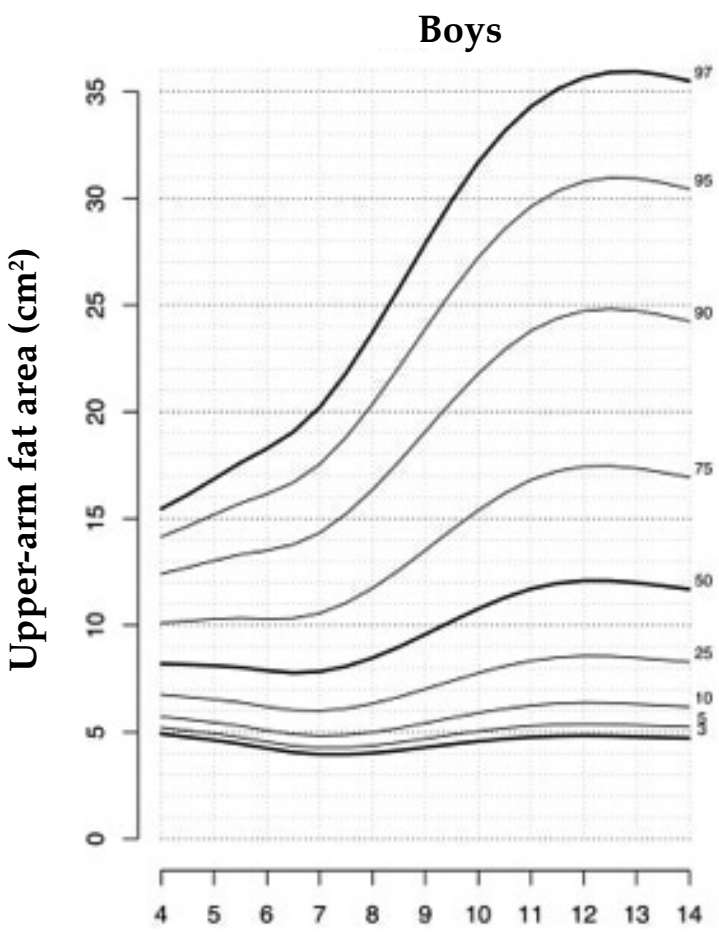

Age (years old)

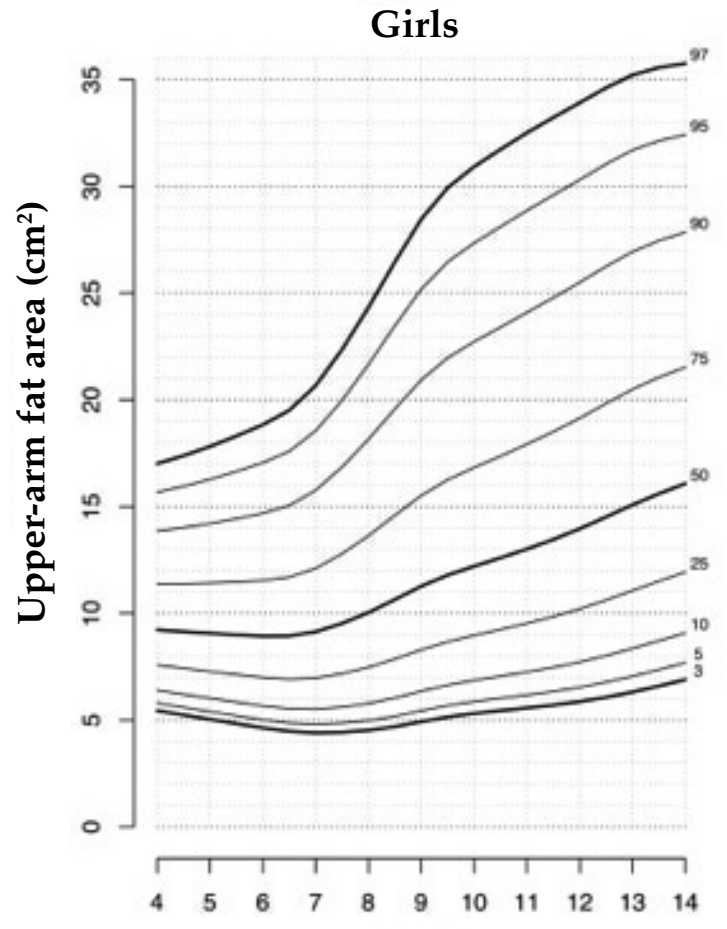

Age (years old)

\section{REFERENCES}

1. Ugochukwu EG. Estimation of total muscle mass from simple anthropometric measurements for adults of Igbo ethnic group of South East Nigeria. Ann Bioanthropol. 2016; 4(2):111-7.

2. Alfaro E, Bejarano I, Dipierri J, Quispe $Y$, et al. Percentilos de peso, talla e índice de masa corporal de escolares jujeños calculados por el método LMS. Arch Argent Pediatr. 2004; 102(6):431-9.

3. BolzánA, Mercer R. Seguridad alimentaria y retardo crónico del crecimiento en niños pobres del norte argentino. Arch Argent Pediatr. 2009; 107(3):221-8.

4. Dahinten SL, Castro LE, Zavatti JR, Forte LM, et al. Growth of school children in different urban environments in Argentina. Ann Hum Biol. 2011; 38(2):219-27.

5. Candelas N, Terán JM, López Barbancho D, Díaz MC, et al. Altitude effect on birth weight and prematurity in the Province of Catamarca (Argentina). Am J Hum Biol. 2015; 27(4):526-9.

6. PajueloJ, Amemiya I. Los indicadores antropométricos del brazo en los niños escolares del Perú. An Fac Med. 1998; 59(1):23-28.

7. Jelliffe DB, Jelliffe EFP. The arm circumference as a public health index of protein-calorie malnutrition of early childhood. J Trop Pediatr (1967). 1969; 15(4):253-60.

8. Lejarraga H, Markevich L, Sanchirico F, Cusminsky M. Reference tables of arm circumference from birth to 12 years of age for Argentinian girls and boys. Arch Latinoam Nutr. 1983; 33(1):139-57.

9. Ayu DR, Aditiawati A, Anzar J, Bahar E. Upper arm circumference measurement for detecting overweight and obesity in children aged 6-7 years. Paediatr Indones. 2017; 57(1):23-9.

10. Chaput JP, Katzmarzyk PT, Barnes JD, Fogelholm M, et al. Mid-upper arm circumference as a screening tool for identifying children with obesity: a 12-country study. Pediatr Obes. 2017;12(6):439-45.

11. Mantilla-Hernández MC, Niño-Bautista L, Prieto-Pinilla EE, Galvis-Padilla D, et al. Validez de la cinta braquial para detección de desnutrición aguda en niñas y niños entre 6 y 59 meses de edad en escenarios de emergencias y desastres. Rev Salud Pública. 2014; 16(2):195-207.

12. Behar AR. La construcción cultural del cuerpo: El paradigma de los trastornos de la conducta alimentaria. RevChilNeuro-Psiquiatr. 2010; 48(4):319-34.

13. Mramba L, Ngari M, Mwangome M, Muchai L, et al. A 
growth reference for mid upper arm circumference for age among school age children and adolescents, and validation for mortality: growth curve construction and longitudinal cohort study. BMJ. 2017; 358:j3423.

14. Reilly JJ. Mid-upper arm circumference (MUAC): new applications for an old measure. Arch Dis Child. 2017; 102(1):1-2.

15. Corvos Hidalgo CA. Evaluación antropométrica del estado nutricional empleando la circunferencia del brazo en estudiantes universitarios. Nutr Clin Diet Hosp. 2011; 31(3):22-7.

16. Rolland-Cachera MF, Brambilla P, Manzoni P, Akrout $\mathrm{M}$, et al. Body composition assessed on the basis of arm circumference and triceps skinfold thickness: a new index validated in children by magnetic resonance imaging. $A m$ J Clin Nutr. 1997; 65(6):1709-13.

17. McDowell MA, Fryar CD, Ogden CL, Flegal KM. Anthropometric reference data for children and adults: United States, 2003-2006. Natl Health Stat Report. 2008; 22(10):1-48.

18. World Health Organization. WHOChild GrowthStandards. Length/heigh-for-age, weight-for-age, weight-for-length, weight-for-height and body mass index-for-age. Methods and development. NLM classification: WS 103. Geneva, Switzerland; 2006. [Accessed on: March $7^{\text {th }}$, 2018]. Available at: http: / / www.who.int/ childgrowth/standards / Technical_report.pdf.

19. World HealthOrganization. WHOChild GrowthStandards: Head Circumference-for-Age, Arm Circumference-for-Age, TricepsSkinfold-for-Age and SubscapularSkinfold-for-Age Methods and Development. Geneva, Switzerland; 2007. [Accessed on: March $7^{\text {th }}, 2018$ ]. Available at: http:/ / www. who.int/childgrowth/standards/second_set/technical_ report_2/en.

20. Frisancho AR. Anthropometric standards. An interactive nutritional reference of body size and body composition for children and adults. Ann Arbor: University of Michigan Press; 2008.

21. Addo OY, Himes JH, Zemel BS. Reference ranges for midupper arm circumference, upper arm muscle area, and upper arm fat area in US children and adolescents aged
1-20 y. Am J Clin Nutr. 2016; 105(1):111-20.

22. Funes Lastra P, Agrelo F, Guita S, Chiquito FC de, et al. Estudio del crecimiento y desarrollo deniños normales dela ciudad de Córdoba a través de una muestra representativa. Córdoba: Ministerio de Bienestar Social, Departamento de Maternidad e Infancia, y Centro de Estudios de Crecimiento y Desarrollo del Niño; 1975.

23. Stewart A, MArfell-Jones M, International Society for the Advancement of Kinanthropometry. International Standards For Anthropometric Assessment. Glasgow, U.K: ISAK; 2011.

24. Cole TJ, Green PJ. Smoothing reference centile curves: the LMS method and penalized likelihood. Stat Med. 1992; 11(10):1305-19.

25. Cole TJ. The British, American NCHS, and Dutch weight standard compared using the LMS method. Am J Hum Biol. 1989; 1(4):397-408.

26. World Health Organization. WHOChild growth standards and the identification of severe acute malnutrition in infants and children: A Joint Statement by the World Health Organization and the United Nations Children's Fund. Geneva, Switzerland; 2009. [Accessed on: April 12 ${ }^{\text {th }}$, 2018]. Available at:http:/ / apps.who.int/iris/bitstream/ha ndle $/ 10665 / 44129 / 9789241598163$ eng.pdf?sequence $=1$.

27. Abdel-Rahman SM, Bi C, Thaete K. Construction of Lambda, Mu, Sigma values for determining mid-upper arm circumference $Z$ scores in U.S. children aged 2 months through 18 years. Nutr Clin Pract. 2017; 32(1):68-76.

28. Marrodán MD, Cabañas MD, Gómez A, González-Montero de Espinosa M, et al. Errores técnicos de medida en el diagnóstico de la desnutrición infantil: datos procedentes de intervenciones de Acción Contra el Hambre entre 2001 y 2010. Nutr Clin Diet Hosp. 2013; 33(2):7-15.

29. Craig E, Bland R, Ndirangu J, Reilly JJ. Use of mid-upper arm circumference for determining overweight and overfatness in children and adolescents. Arch Dis Child. 2014;99(8):763-6.

30. Guimarey LM, Castro LE, Torres MF, Cesani MF, et al. Secular changes in body size and body composition in schoolchildren from La Plata city (Argentina). Anthrop Anz. 2014;71(3):287-301. 